\title{
ESTUDO DA INFLUÊNCIA DO TAMANHO DE GRÃO SOBRE O COMPORTAMENTO DE CORROSÃO DA LIGA DE MAGNÉSIO AZ91D*
}

\section{Resumo}

Letícia dos Reis Gonçales ${ }^{1}$ Lucas Costa de Castro Ferraz ${ }^{1}$ Olandir Vercino Correa ${ }^{2}$ Renato Altobelli Antunes ${ }^{3}$

A liga AZ91D apresenta $9 \% p A I$ e $1 \% p Z n$ e pode ser submetida a tratamento térmico de solubilização seguido de envelhecimento para melhoria de propriedades mecânicas por meio de precipitação da fase beta- $\mathrm{Mg}_{17} \mathrm{Al}_{12}$. Esta fase, porém, pode ter efeitos distintos sobre o comportamento de corrosão da liga. Buscando estudar a influência do tamanho de grão da matriz alfa e a presença de precipitados beta sobre a resistência à corrosão da liga AZ91D, este trabalho utilizou lingotes com estrutura bruta de fusão na obtenção de amostras solubilizadas, laminadas a frio e então envelhecidas, para subsequente análise microestrutural e do comportamento de corrosão. A solubilização ocorreu a $445^{\circ} \mathrm{C}$ por $24 \mathrm{~h}$ e foi efetiva em dissolver quase completamente a fase beta. A laminação levou a uma redução de $20 \%$ da espessura das amostras e de 400 para $130 \mu \mathrm{m}$ o tamanho de grão médio, após envelhecimento. O envelhecimento feito a $200^{\circ} \mathrm{C}$ em $2 \mathrm{e}$ 24h permitiu a precipitação de fase beta em maior quantidade e melhor distribuição por contornos de grão em relação às amostras fundidas ou solubilizadas. Ensaios de imersão foram realizados, apontando uma leve queda na taxa média de corrosão quando se lamina a amostra, enquanto as amostras solubilizadas (sem fase beta) mostraram maior susceptibilidade à corrosão. Assim, é possível indicar que o refinamento de grãos é benéfico ao formar uma rede de proteção em ligas de magnésio AZ91D, apesar de introduzir defeitos gerados pela laminação

Palavras-chave: AZ91D; Fase beta; Laminação a frio; Resistência à corrosão.

\section{STUDY OF GRAIN SIZE INFLUENCE ON THE CORROSION BEHAVIOR OF AZ91D MAGNESIUM ALLOY}

\begin{abstract}
The AZ91D, one of the first magnesium alloys to be commercialized, presents $9 w t \% A l$ e $1 \mathrm{wt} \% \mathrm{Zn}$ and can be solution-treated followed by ageing to improve mechanical properties by precipitating beta phase- $\mathrm{Mg}_{17} \mathrm{Al}_{12}$. However, this phase can lead to different effects over the corrosion mechanisms. In order to study the influence of the grain size of alpha matrix and the presence of beta precipitates on corrosion, this work used AZ91D ingots to obtain solution-treated, cold rolled and then aged samples to subsequent microstructure and corrosion analysis. Solution heat treatment occurred at $445^{\circ} \mathrm{C}$ for $24 \mathrm{~h}$ and was effective on the dissolution of beta phase. Cold rolling took to a $20 \%$ thickness reduction of samples and from 400 to $130 \mu \mathrm{m}$ the average grain size, after ageing. Ageing occurred at $200^{\circ} \mathrm{C}$ for 2 and $24 \mathrm{~h}$ causing beta phase precipitation along the grain boundaries in higher quantity and better distribution compared to as cast and solubilized conditions. Immersion test was performed pointing a slight drop in the average corrosion rates for cold rolled samples, whereas solution-treated samples (with no beta phase) showed to be more susceptible to corrosion. Therefore, it is possible to infer that grain refinement has a positive effect on corrosion resistance of AZ91D magnesium alloy through the formation of a protective net of beta phase, despite of the introducing cold rolling defects.

Keywords: AZ91D; Beta Phase; Cold Rolling; Corrosion Resistance.

Bacharel em Engenharia de Materiais, Universidade Federal do ABC, Santo André, SP, Brasil.

Licenciado em Química, Técnico em Metalurgia, Técnico de Laboratório, IPEN/CNEN, São Paulo, SP,Brasil.

Eng. de Materiais, Mestre e Doutor em Tecnologia Nuclear - Materiais, Professor adjunto do Centro de Engenharia, Modelagem e Ciências Sociais Aplicadas, Universidade Federal do ABC, Santo André, SP, Brasil.
\end{abstract}




\section{INTRODUÇÃO}

O magnésio apresenta alta resistência específica e baixa densidade $\left(1,7 \mathrm{~g} / \mathrm{cm}^{3}\right)$, 0 que o torna um material promissor em aplicações como componentes de computador, de celulares e aeroespaciais. Sua estrutura cristalina é hexagonal compacta e seu módulo de elasticidade é $45 \mathrm{GPa}$. Apesar destas características, magnésio puro é pouco utilizado para aplicações estruturais. Para a maior parte das aplicações, alumínio (Al), zinco $(\mathrm{Zn})$, manganês $(\mathrm{Mn})$ e terras raras são os principais elementos usados no desenvolvimento de ligas de magnésio, conferindo resistência mecânica e à corrosão. [1-3]

À temperatura ambiente, o magnésio e suas ligas apresentam baixa ductilidade devido à falta dos cinco sistemas primários de deslizamento necessários segundo o critério de Von Mises. Em temperatura ambiente, o escorregamento está limitado ao plano basal (0001) na direção $\langle 11 \overline{20}\rangle$. Em temperaturas mais elevadas, acima de $225^{\circ} \mathrm{C}$, são ativados os planos prismáticos de primeira ordem $\{11 \overline{22}\}$ nas direções $\langle 1 \overline{123}$ ) e os planos piramidais de segunda ordem $\{10 \overline{10}\}$ nas direções $\langle 11 \overline{20}\rangle$ provocando um aumento da ductilidade e possibilitando processos de conformação mais severos, como laminação a quente e extrusão. Assim, a baixas temperaturas, não sendo possível a deformação por escorregamento de sistemas, a maclação é favorecida, e com aumento de temperatura e ativação de novos planos de escorregamento, as maclas podem desaparecer. Por estes motivos, a maioria dos métodos de fabricação se dá por fundição, com uma temperatura de fusão em torno de $650^{\circ} \mathrm{C}$, ou por trabalho a quente, $\left(200-350^{\circ} \mathrm{C}\right)$. $^{[1-3]}$

O maior desafio para a produção industrial e aplicação do magnésio e suas ligas é sua baixa resistência à corrosão. A liga AZ91, em particular, apresenta 8-9\%p de Al e $1 \%$ p de Zn e é bastante utilizada na indústria automotiva. Quando em alta pureza, está entre as ligas de magnésio de maior resistência à corrosão, além de sua alta conformabilidade e resistência à fadiga relativamente elevada. Ainda assim, seu potencial eletroquímico padrão é de -2,4V (NHE), e em solução aquosa de -1,5V devido à formação de $\mathrm{Mg}(\mathrm{OH})_{2}$. Estudos atuais focam nos fatores e mecanismos envolvidos nos processos de corrosão desta liga com intuito de aumentar sua resistência à degradação [4].

Vários estudos mostram que o comportamento de corrosão das ligas de $\mathrm{Mg}$ é dependente da microestrutura e, em particular, da quantidade e distribuição das fases intermetálicas e do tamanho de grão ${ }^{[1-4]}$. Em ligas AZ91D as três fases presentes são a a (solução sólida contendo $\mathrm{Al}$ e $\mathrm{Zn})$, a $\beta\left(\mathrm{Mg}_{17} \mathrm{Al} \mathrm{l}_{12}\right)$ e uma fase intermetálica contendo $\mathrm{Mn}$ e Al. A corrosão nesta liga, ocorre principalmente no centro da matriz a-Mg pobre em alumínio ou em interfaces entre a matriz e constituintes intermetálicos grosseiros e muito localizados. Intermetálicos, em especial a fase $\beta$, podem atuar como catodos numa corrosão microgalvânica com a fase $\alpha$ menos nobre. No entanto, a fase $\beta$ também pode atuar como uma barreira contra corrosão e sítio preferencial de crescimento de grãos refinados, podendo desacelerar o avanço da corrosão ${ }^{[3-4]}$. Trabalhos anteriores do grupo de pesquisa indicaram que o tratamento de envelhecimento após solubilização propicia a precipitação de fase beta nos contornos dos grãos alfa em maior quantidade e melhor distribuição com aumento do tempo. A formação desta rede protetora de fase beta leva ao aumento da resistência à corrosão da liga, segundo demonstram ensaios de imersão realizados pelo grupo. ${ }^{[5]}$ 
Outra abordagem para aumento da resistência à corrosão está no refinamento de grãos. Segundo indicação da literatura, a liga AZ91D com grãos mais finos tem maior resistência à corrosão em comparação com a microestrutura mais grosseira [1]. Este trabalho teve como objetivo obter amostras de ligas de magnésio AZ91D solubilizadas, laminadas e envelhecidas a fim de avaliar a influência da microestrutura obtida sobre a resistência à corrosão deste material, mais especificamente do efeito do tamanho de grão.

\section{MATERIAIS E MÉTODOS}

A liga AZ91D foi recebida na forma de lingote com estrutura bruta de fusão. Foram obtidas amostras em formato quadrado com área de aproximadamente $1 \mathrm{~cm}^{2}$ utilizando cortador metalográfico do tipo cut-off.

As amostras foram primeiramente submetidas a tratamento térmico de solubilização a $445^{\circ} \mathrm{C}$ por $24 \mathrm{~h}$ em forno tubular com atmosfera de argônio, seguida de têmpera em água. A laminação foi realizada a temperatura ambiente em um laminador duo reversível (Máquinas Coelho Série 005 427, Modelo LE150) até 20\% de redução da espessura. Em seguida, as amostras foram tratadas termicamente por envelhecimento a $200^{\circ} \mathrm{C}$ por $2 \mathrm{~h}$ e 24 h, em atmosfera de argônio, utilizando forno tubular.

Para análise microestrutural, as amostras foram embutidas em baquelite e preparadas metalograficamente com a sequência de lixamento \#220, \#320, \#400, \#600 e por fim, \#2400. Em seguida, foi feito polimento utilizando pasta de diamante de $6 \mu \mathrm{m}$ e $1 \mu \mathrm{m}$. O ataque químico foi preparado utilizando $75 \mathrm{~mL}$ de álcool etílico absoluto, $25 \mathrm{~mL}$ de água deionizada, $1 \mathrm{~mL}$ de ácido nítrico e $1 \mathrm{~mL}$ de ácido acético glacial, por 45 a 90s, seguindo a literatura [6][7]. Para análise microestrutural foi utilizado um microscópio óptico Olympus e a determinação do tamanho de grão foi realizada com base na norma ASTM E112, pelo método do intercepto linear. As amostras também foram analisadas por microscópio eletrônico de varredura de bancada, Hitachi TM3000, com equipamento de microanálise EDS acoplado para identificação das fases pela composição química.

Para realização do ensaio de imersão, as amostras foram lixadas em todas as suas faces com lixas de SiC de granulometria de \#220 para remoção de artefatos superficiais introduzidos durante a laminação e da camada externa oxidada. As amostras foram medidas e pesadas para efeitos de cálculo, e em seguida foram submetidas a imersão em solução de $\mathrm{NaCl} 3,5 \%$, com base na norma ASTM-G31, por um período de 16 dias em temperatura ambiente. Após este período as amostars foram limpas utilizando uma solução de $200 \mathrm{~g} / \mathrm{L}$ de $\mathrm{CrO}_{3}$ e $10 \mathrm{~g} / \mathrm{L}$ de $\mathrm{AgNO}_{3}$ de acordo com a ASTM G1-90 [8] lavadas com acetona, secas e novamente medidas e pesadas.

\section{RESULTADOS E DISCUSSÃO}

\subsection{Análise Microestrutural}

A análise de microscopia eletrônica por varredura (MEV) permitiu estudar a microestrutura bruta de fusão das amostras como recebidas (Figura 1a) destacando as três fases presentes: $\alpha$ (Mg contendo $\mathrm{Al}$ e $\mathrm{Zn}), \beta\left(\mathrm{Mg}_{17} \mathrm{Al}_{12}\right)$ e uma fase intermetálica contendo $\mathrm{Mn}$ e Al. Após tratamento de solubilização há dissolução da fase beta. Com posterior tratamento de envelhecimento, há nova precipitação da 
fase beta, preferencialmente nos contornos de grão, distribuído em forma de rede, como se pode notar na amostra solubilizada e tratada a $200^{\circ} \mathrm{C} / 24 \mathrm{~h}$ da Figura $1 \mathrm{~b}{ }^{[5]}$
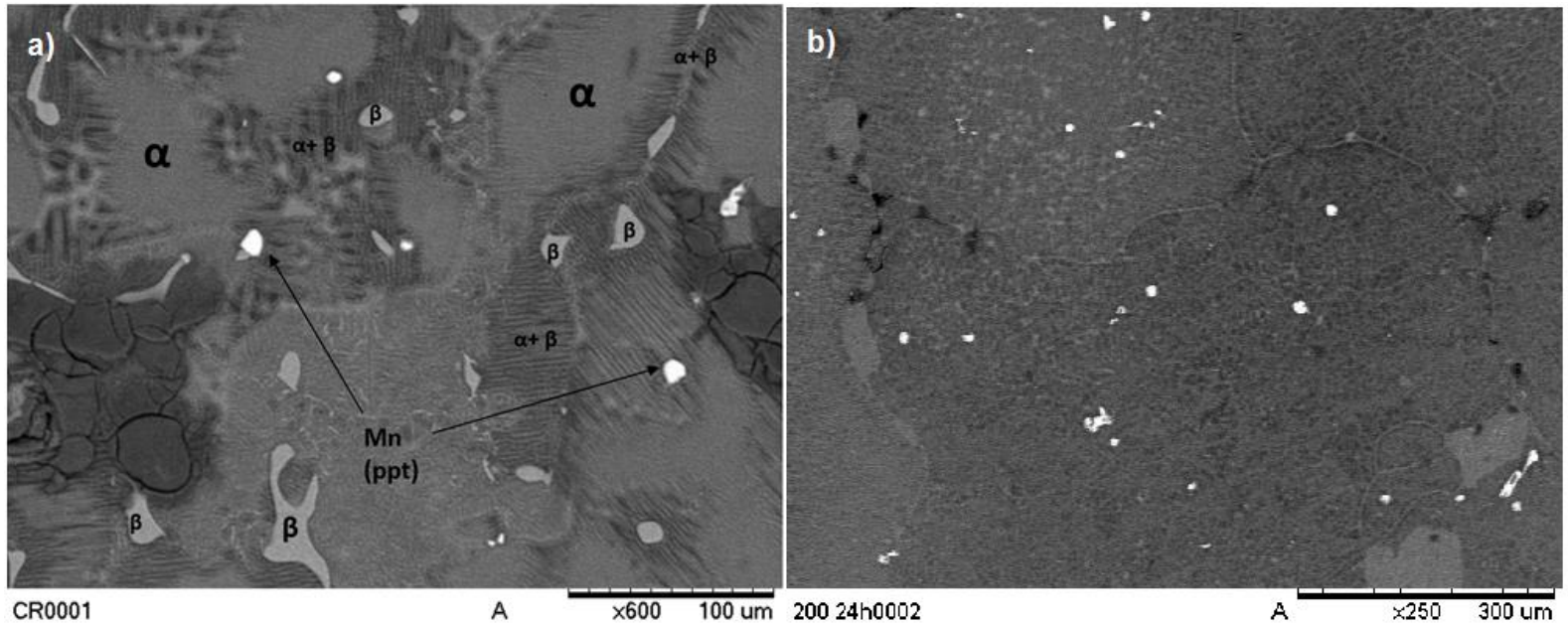

Figura 1: (a) Micrografia eletrônica por varredura da amostra como recebida (estrutura bruta de fusão) com 600x de aumento, mostrando a matriz de fase $\alpha$, fase $\beta$ descontínua e fase eutética lamelar de $\alpha+\beta$. (b) Micrografia da liga AZ91D solubilizada e envelhecida a $200^{\circ} \mathrm{C}$ e $24 \mathrm{~h}$ ampliada em 250x, apontando precipitação contínua de fase beta pelos contornos de grão. Em ambas podem ser vistos precipitados Al-Mn, mais claros pelo contraste da técnica. ${ }^{[5]}$

A Figura 2 traz a espectroscopia por energia dispersiva (EDS) da amostra solubilizada e envelhecida por $200^{\circ} \mathrm{C}$ e $2 \mathrm{~h}$. Além comprovar a composição da liga, o EDS revelou os precipitados que se destacam por serem mais claros nas análises de MEV como sendo compostos por $\mathrm{Al} \mathrm{e} \mathrm{Mn}^{[5]}$ como encontrado na literatura ${ }^{[3]}$ Como estes precipitados foram encontrados em todas as amostras, não há uma análise de seu efeito sobre o comportamento corrosivo da liga, além de não ser o foco desta pesquisa.

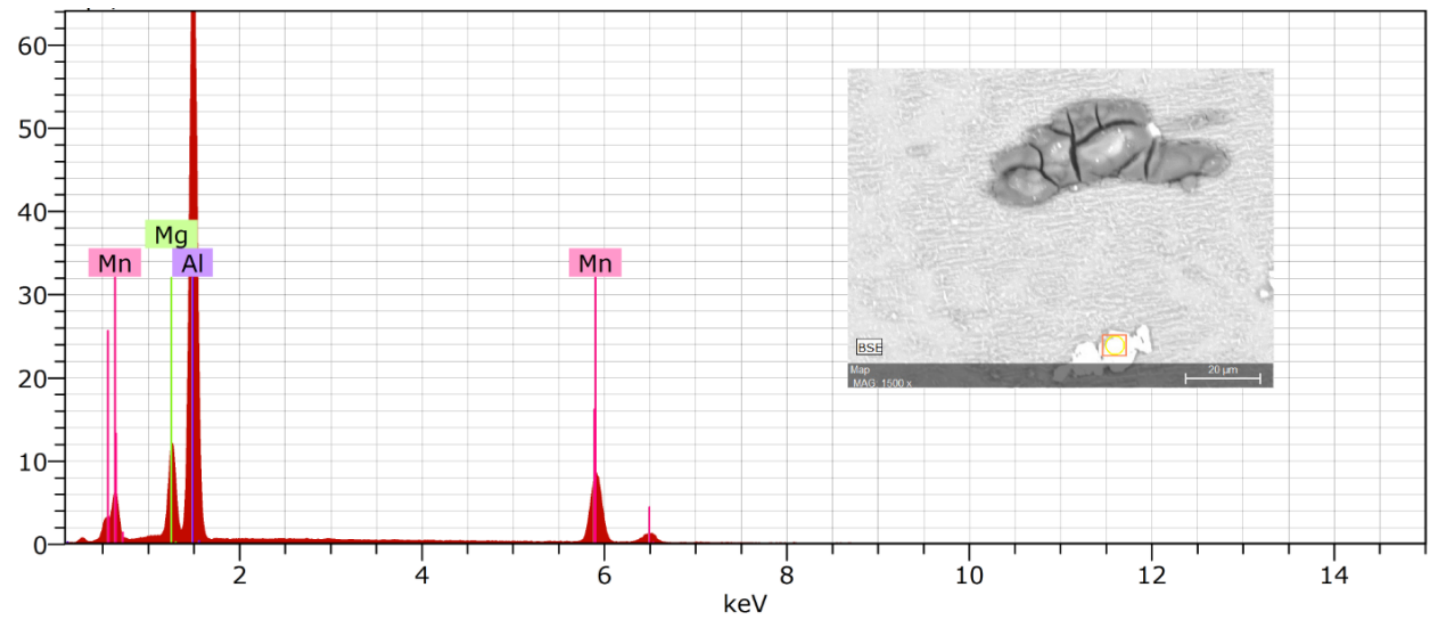

Figura 2: Espectro de EDS do precipitado de Al-Mn indicando maiores teores de alumínio e manganês na amostra $200^{\circ} \mathrm{C}-2 \mathrm{~h}$. [5]

$\mathrm{Na}$ microscopia óptica das Figuras $3(\mathrm{a})$ e (b) referentes à amostra somente solubilizada e laminada, é visível o aparecimento de microtrincas, como esperado para deformações acima de $5 \%$ de redução de espessura ${ }^{[9]}$. 
Além disso, foi verificado o surgimento de pites a olho nu imediatamente após a retirada da amostra da lixa rotacional resfriada por água durante sua preparação. Este efeito foi comprovado pelas marcas de pites evidentes na microscopia óptica. A literatura menciona que o surgimento de pites é comum em ligas $\mathrm{Mg}-\mathrm{Al}$ solubilizadas, de microestrutura composta basicamente por $\alpha-M g$ grosseira, sem proteção por precipitados $\beta$ e refinamento de grãos ${ }^{[1,10,11,12]}$.
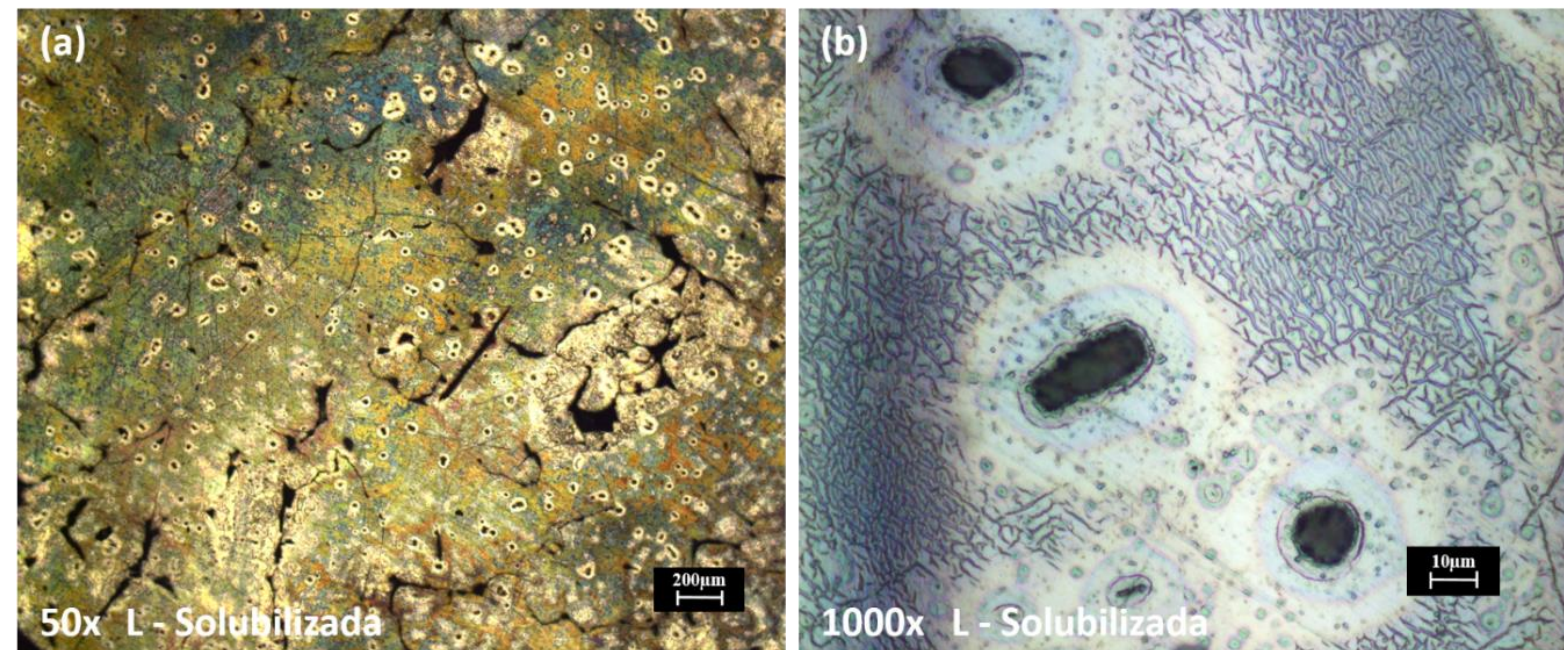

Figura 3. Micrografias de ampliação (a) 50x, (b) 1000x da amostra solubilizada e laminada. $O$ ataque químico foi ineficaz em revelar a microestrutura. Há trincas e marcas típicas de corrosão por pites..$^{[5]}$

A análise microestrutural por microscopia óptica permitiu evidenciar a redução do tamanho de grão das amostras submetidas à laminação, comparando as Figuras 4a e Figuras $5 a$ e 5b, com amostras não laminadas, conforme exemplo apresentado na Figura 4b. Outra grande diferença é a presença de defeitos introduzidos pela laminação a frio, como trincas e marcas de escorregamento, que é o principal mecanismo de deformação de ligas de magnésio. [9] É notável a diminuição do tamanho de grão e a inserção de defeitos pela laminação (Figura 4a) quando comparada com a condição não laminada (Figura 4b). Porém, não se identifica um alinhamento preferencial dos grãos pela laminação, que ocorreria num material mais dúctil ou se a conformação fosse a quente. Neste caso, é provável que a fragilidade do magnésio pela limitação do escoamento por planos basais ${ }^{[9]}$ tenha impedido o alongamento significativo dos grãos. As linhas com direções específicas e limitadas pelos contornos de grão ao longo de toda a amostra sugerem marcas dos planos de escorregamento que é o principal mecanismo de deformação deste material. 

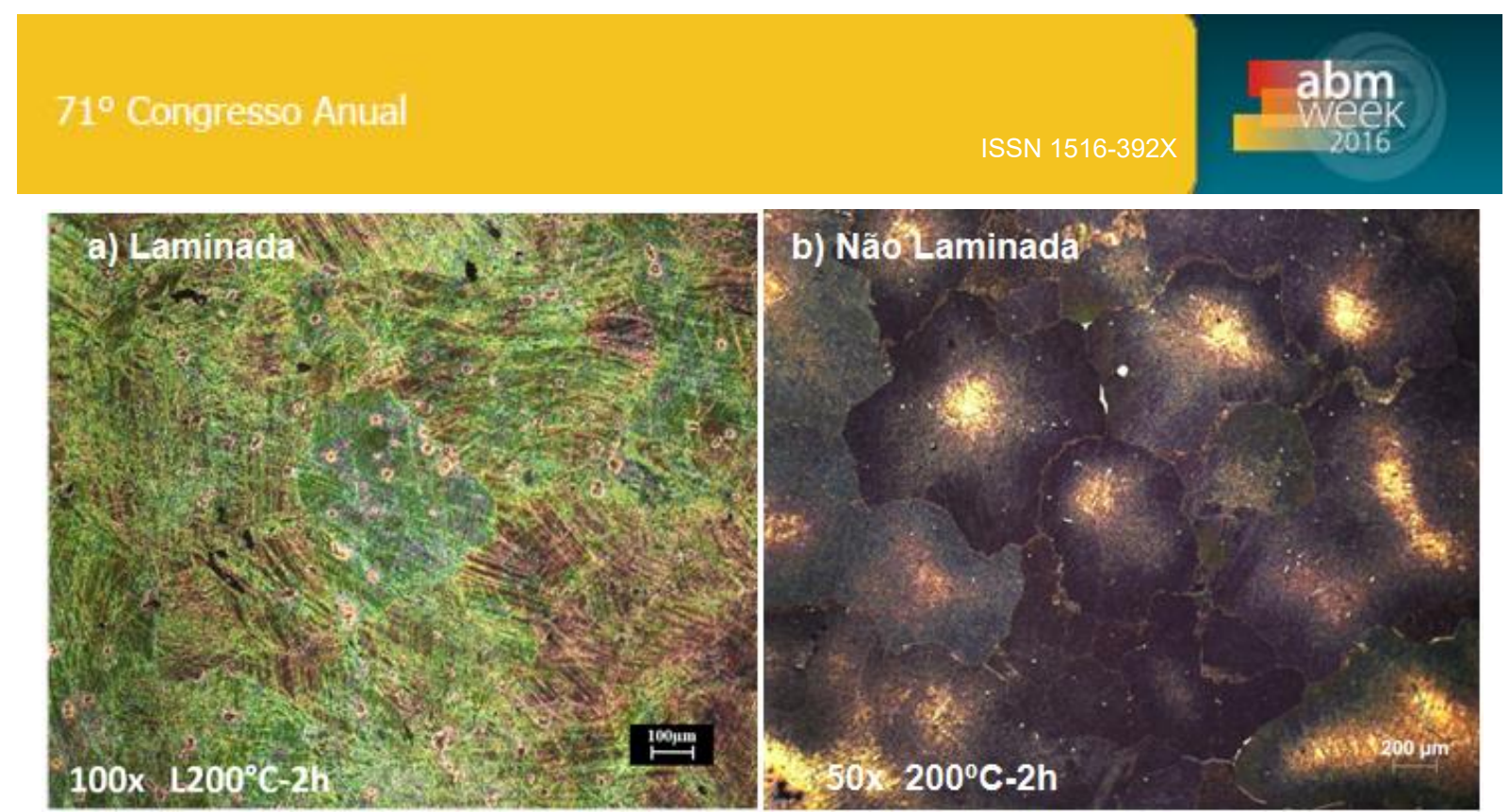

Figura 4. Micrografias de ampliação (a) $100 x$ da amostra laminada e tratada a $200^{\circ} \mathrm{C}$ por $2 \mathrm{~h}$ e (b) $50 \mathrm{x}$ da amostra não laminada mas envelhecida de trabalhos anteriores, com eficácia do ataque químico.[5]

$\mathrm{Na}$ micrografia da Figura 5, referente à uma amostra laminada e envelhecida por 24h, notam-se com maior clareza os contornos de grão, marcas de planos de escorregamento e precipitados da fase $\beta$, nos contornos, e de Al-Mn.
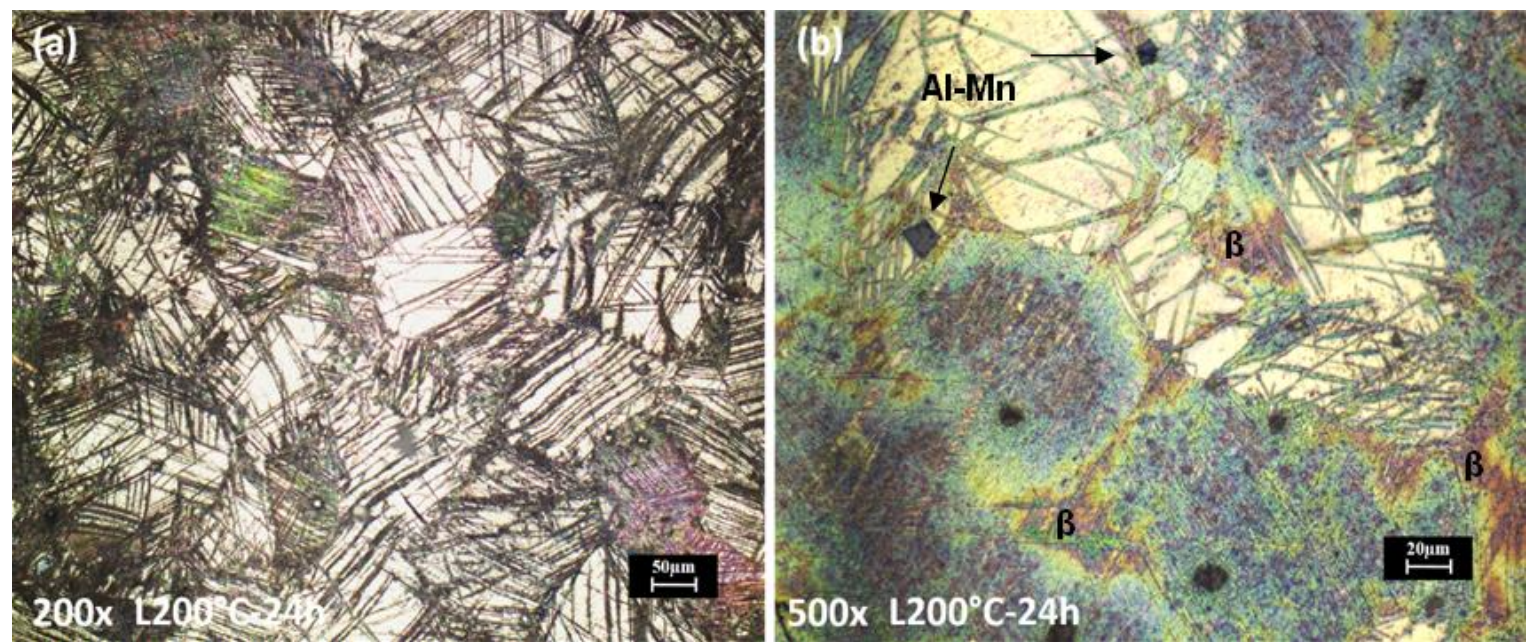

Figura 5. Micrografias de ampliação (a) 200x e (b) 500x da amostra laminada e envelhecida por 24h. Há marcas de planos de escorregamento, precipitado $\beta$ e Al-Mn e destaque de contornos de grão. [5]

A Tabela 1 apresenta uma comparação entre o tamanho de grão das amostras laminadas e não laminadas com condições de tratamento térmico idênticas. Podeser observar que houve uma redução significativa do tamanho de grão de $400 \mu \mathrm{m}$ para $130 \mu \mathrm{m}$.

Tabela 1. Tamanhos de grão médio pelo método do intercepto linear [5]

\begin{tabular}{ccc}
\hline Condição* $^{*}$ & Diâmetro Médio $(\mu \mathrm{m})$ & Número de Grão médio \\
\hline $200^{\circ} \mathrm{C}-2 \mathrm{~h}$ & $415 \pm 34$ & $19,2 \pm 0,2$ \\
\hline $\mathrm{L} 200^{\circ} \mathrm{C}-2 \mathrm{~h}^{* *}$ & $106 \pm 0$ & $23,1 \pm 0,0$ \\
\hline $200^{\circ} \mathrm{C}-24 \mathrm{~h}$ & $406 \pm 36$ & $19,3 \pm 0,2$ \\
\hline $\mathrm{L} 200^{\circ} \mathrm{C}-24 \mathrm{~h}$ & $133 \pm 5$ & $22,5 \pm 0,1$
\end{tabular}

${ }^{*}$ Amostras laminadas indicadas por $L$ seguida pela condição de tratamento térmico.

${ }^{* *}$ Apenas uma imagem de qualidade pôde ser analisada 


\subsection{Corrosão}

A Figura 6 traz o aspecto visual das amostras após serem submetidas a ensaio de imersão por 16 dias em uma solução aquosa de $\mathrm{NaCl} 3,5 \%$ p.
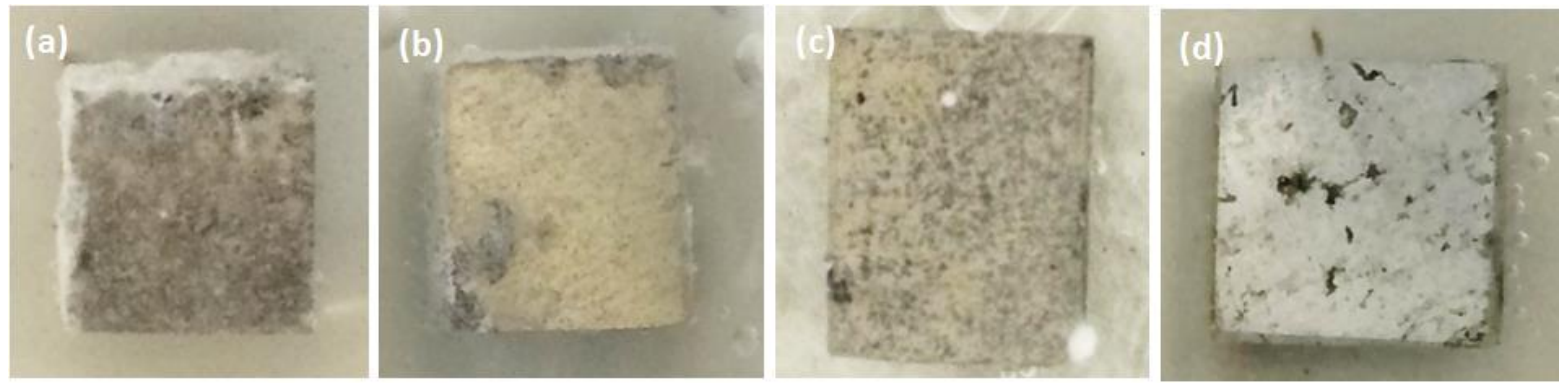

Figura 6: Aspecto visual das amostras após ensaio de corrosão. (a) Amostra como recebida em sua estrutura bruta de fusão, (b) Amostra solubilizada à $445^{\circ} \mathrm{C}$ por $24 \mathrm{~h}$ (c) Amostra solubilizada, laminada e envelhecida a $200^{\circ} \mathrm{C}$ por $2 \mathrm{~h}$. (d) Amostra solubilizada, laminada e envelhecida a $200^{\circ} \mathrm{C}$ por $24 \mathrm{~h} .{ }^{[5]}$

Visualmente, nota-se uma corrosão superficial mais homogênea e severa nas amostras como recebida e solubilizada, Figuras 6 (a) e (b), além de serem marcadas por pites profundos. A amostra envelhecida a $200^{\circ} \mathrm{C}$ por $2 \mathrm{~h}$, Figura 6 (c), também apresentou corrosão superficial mas menos severa que as anteriores. A amostra envelhecida a $200^{\circ} \mathrm{C}$ por $24 \mathrm{~h}$, Figura 6 (d), demonstrou o melhor resultado com aspecto brilhoso da preparação parcialmente mantido, indicando ausência ou leve corrosão superficial, mas apresentou a presença de pites, porém menos profundos do que os presentes nas as amostras anteriores. Além disso, a quantidade de produto de corrosão desprendido para a solução de ensaio no fundo dos recipientes para amostras como recebida e solubilizada, Figuras 6 (a) e (b), foi muito maior que para as amostras laminadas e envelhecidas, Figuras 6 (c) e (d), indicando que as amostras envelhecidas foram menos susceptíveis ao processo de corrosão.

$\mathrm{Na}$ Tabela 2 são apresentados os dados de perda de massa obtidos pelo ensaio de imersão das amostras como recebida, solubilizadas laminadas e não laminadas, e amostras submetidas a envelhecimento com a condição indicada, precedida por "L" caso tenham sido laminadas anteriormente ao envelhecimento. Neste caso, o cálculo da taxa de corrosão não foi considerado como método quantitativo confiável, uma vez que não é indicada para materiais que sofrem corrosão localizada, como é o caso da liga estudada neste trabalho.

Tabela 2. Comparação entre perdas de massa equivalentes obtidas pelo teste de imersão das amostras como recebida, solubilizadas, tratadas, laminadas e não laminadas.

\begin{tabular}{cc}
\hline Condição & Perda de Massa \\
\hline Como Recebidas & $0.83 \% \pm 2,05 \%$ \\
\hline Solub. & $4,44 \% \pm 2,05 \%$ \\
\hline LSolub. & $4,92 \% \pm 3,37 \%$ \\
\hline $200^{\circ} \mathrm{C}-2 \mathrm{~h}$ & $0,31 \% \pm 0,24 \%$ \\
\hline $\mathrm{L} 200^{\circ} \mathrm{C}-2 \mathrm{~h}^{*}$ & $0,45 \% \pm 0,20 \%$ \\
\hline $200^{\circ} \mathrm{C}-24 \mathrm{~h}$ & $0,39 \% \pm 0,04 \%$ \\
\hline $\mathrm{L} 200^{\circ} \mathrm{C}-24 \mathrm{~h}^{*}$ & $0,15 \% \pm 0,09 \%$ \\
\hline
\end{tabular}

${ }^{*}$ Amostras laminadas indicadas por L seguida pela condição de tratamento térmico de envelhecimento.

Os dados da Tabela 2 são um claro indicativo da capacidade do tratamento de envelhecimento em reduzir a susceptibilidade à corrosão pela expressiva redução de perda de massa ante os resultados das amostras não envelhecidas, como as recebidas e solubilizadas. Os grandes valores de perda de massa das amostras 
solubilizadas, tanto laminadas ou não, em relação às demais, pode ser atribuído à ausência da fase $\beta$ protetiva. Esta fase, presente nas amostras como recebida eenvelhecidas, é capaz de formar uma barreira física contra o avanço da corrosão. Quando a fase $\beta$ se encontra bem distribuída ao longo dos contornos da matriz $\alpha$, que é o caso das amostras envelhecidas, esta rede de proteção é mais efetiva, levando a uma resistência à corrosão mais elevada do que a estrutura bruta de fusão da amostra como recebida, que apesar de apresentar fase $\beta$, está localizada, o que está de acordo com a literatura [11,12,14].

Os resultados mostram uma pequena queda na perda de massa quando se lamina a amostra no caso das amostras envelhecidas por 24h. As demais apresentam altos valores de desvio-padrão impossibilitando outras comparações. Uma hipótese é de que, apesar da maior suceptibilidade à corrosão decorrente dos defeitos inerentes à laminação, a redução do tamanho de grão teria o efeito oposto, compensando ou até superando a perda de resistência provocada pelos defeitos mencionados. Este fato condiz com trabalhos da literatura que indica que o refino de grão é favorável para o aumento da resistência à corrosão ${ }^{[1,10,12]}$.

\section{CONCLUSÃO}

A análise microestrutural da liga AZ91D submetida ao processo de laminação revelou eficácia na redução de tamanho de grão médio de 400 para $130 \mu \mathrm{m}$ pelo trabalho a frio seguido de envelhecimento. Também evidenciou marcas de microtrincas e corrosão por pites, mais evidente em amostras somente solubilizadas devido à maior fração de fase alfa, menos nobre, ficando estas cada vez menos evidentes conforme maior o tempo de envelhecimento das amostras. Isso ocorre provavelmente devido a eventos térmicos como ativação de sistemas de escorregamento que recuperam alguns destes defeitos, como maclas e microtrincas, reduzindo a elevada energia de deformação acumulada. Os resultados do ensaio de imersão sugerem uma redução na perda de massa para as amostras envelhecidas e laminadas, apontando efeito benéfico da redução do tamanho de grão pelo aumento da resistência à corrosão após laminação. Acredita-se este efeito seja decorrente da formação de uma barreira física contra a corrosão pela precipitação de fase $\beta$ $\mathrm{Mg}_{17} \mathrm{Al}_{12}$ melhor distribuída nos contornos de grão, devido ao maior refinamento dos grãos pela laminação, durante o tratamento de envelhecimento.

\section{Agradecimentos}

À Universidade Federal do $\mathrm{ABC}$ e corpo de técnicos pelo suporte. À Rima Industrial Magnésio por prover as placas de AZ91D utilizadas neste trabalho.

\section{REFERÊNCIAS}

1 Alvarez-Lopez M, Pereda MD, del Valle JA, Fernandez-Lourenzo M, Garcia-Alonso MC, Ruano OA et al. Corrosion behaviour of AZ31 magnesium alloy with different grain sizes in simulated biological fluids, Acta Biomaterialia, 2010; 6: 1763-1771.

2 Callister Jr WD, Materials Science And Engineering: An Introduction. Edição 7. New York: John Wiley \& Sons; 2007.

3 Friedrich HE, Mordike, BL. Magnesium Technology: Metallurgy, Design Data, Automotive Applications, Springer, Berlin Heidelberg: Springer Science \& Business Media; 2006. 
4 Correa PS. Comportamento Corrosivo da Liga de Magnésio AZ91D Revestidas com Filmes de Metiltrietóxi Silano e ĺons de Cério. [Dissertação de Mestrado] Porto Alegre: Univesidade Federal do Rio Grande do Sul; 2008.

5 Gonçales LR, Ferraz LCC. Estudo da Influência do Tamanho de Grão e da Distribuição de Precipitados Sobre o Comportamento de Corrosão da Liga de Magnésio AZ91D [Trabalho de Graduação] Santo André: Universidade Federal do ABC; 2015.

6 Voort GV.Metallography of Magnesium and its Alloys.Buehler Tech Notes.2015;4(2):1-5

7 Maltais AA, Dube D, Fiset M, Larochea G, Turgeonb S. Improvements in the metallography of as-cast AZ91 alloy. Materials Characterization. 2004; 52: 103-119.

8 ASTM G1-90 (Reapproved 1994): Standard practice for preparing, Cleaning, and Evaluating Corrosion Test Specimens. Annual Book of ASTM Stands, American Society for Testing and Materials, Philadelphia; 1992.

9 Degarmo EP, Black JT, Kohser RA, Materials and Processes in Manufacturing. Edição 9. New York: Wiley, 2003.

10 Aung NN, Zhou W. Effect of heat treatment on corrosion and electrochemical behaviour of AZ91D magnesium alloy. Journal of Applied Electrochemistry. 2002; 32: 1397-1401

11 Ricketts N. Properties of Cast Magnesium Alloys. [acesso em 07 abril 2015] Disponível em: http://mg.tripod.com/asm_prop.htm

12 Ambat R, Aung NN, Zhou W. Studies on the influence of chloride ion and pH on the corrosion and electrochemical behaviour of AZ91D magnesium alloy, Journal of Applied Electrochemistry. 2000; 30: 865-874.

13 Song G, Atrens A, Dargusch M. Influence of microstructure on the corrosion of die cast AZ91D. Corrosion Science. 1999; 41: 249-273.

14 Song G, Bowles AL, Stjohn DH. Corrosion resistance of aged die cast magnesium alloy AZ91D. Materials Science and Engineering. 2004; A 366: 74-86. 